\title{
ARTICLE OPEN Mechanotransduction via the coordinated actions of integrins, PI3K signaling and Connexin hemichannels
}

\author{
Manuel A. Riquelme ${ }^{1}$, Sumin $\mathrm{Gu}^{1}$, Rui Hua ${ }^{1}$ and Jean X. Jiang $\mathbb{D}^{1}$
}

Mechanical loading opens connexin $43(\mathrm{Cx} 43)$ hemichannels (HCs), leading to the release of bone anabolic molecules, such as prostaglandins, from mechanosensitive osteocytes, which is essential for bone formation and remodeling. However, the mechanotransduction mechanism that activates $\mathrm{HCs}$ remains elusive. Here, we report a unique pathway by which mechanical signals are effectively transferred between integrin molecules located in different regions of the cell, resulting in $\mathrm{HC}$ activation. Both integrin a5 and aV were activated upon mechanical stimulation via either fluid dropping or flow shear stress (FSS). Inhibition of integrin aV activation or ablation of integrin a5 prevented $\mathrm{HC}$ opening on the cell body when dendrites were mechanically stimulated, suggesting mechanical transmission from the dendritic integrin aV to a5 in the cell body during $\mathrm{HC}$ activation. In addition, HC function was compromised in vivo, as determined by utilizing an antibody blocking aV activation and a5-deficient osteocyte-specific knockout mice. Furthermore, inhibition of integrin aV activation, but not that of a5, attenuated activation of the phosphoinositide 3-kinase (PI3K)-protein kinase B (AKT) signaling pathway upon mechanical loading, and the inhibition of PI3K/AKT activation blocked integrin a5 activation and $\mathrm{HC}$ opening. Moreover, $\mathrm{HC}$ opening was blocked only by an anti-integrin aV antibody at low but not high FSS levels, suggesting that dendritic aV is a more sensitive mechanosensor than a5 for activating HCs. Together, these results reveal a new molecular mechanism of mechanotransduction involving the coordinated actions of integrins and PI3K/ AKT in osteocytic dendritic processes and cell bodies that leads to HC opening and the release of key bone anabolic factors.

Bone Research (2021)9:8 ; https://doi.org/10.1038/s41413-020-00126-w

\section{INTRODUCTION}

Bone continuously undergoes remodeling, which helps to maintain the proper structure and organization of the tissue. Mechanical loading, induced by healthy physical activity, promotes bone formation, and remodeling in association with enhancement of bone mass and strength. ${ }^{1}$ Osteocytes, the most abundant bone cell type, are thought to be the most likely mechanosensory cells in bone. Osteocytes were recently suggested to be the main factor regulating bone remodeling by orchestrating the functions of other bone cells as well as the remodeling of the bone matrix and are a potential therapeutic target for the treatment of osteoporosis. ${ }^{2-4}$ Osteocytes are embedded inside the bone mineral matrix, and the long dendritic processes of osteocytes form a network among neighboring osteocytes and cells on the bone surface. ${ }^{5}$ Osteocyte cell bodies and processes are surrounded by a fluid-filled space, creating an extensive lacunae-canalicular network. ${ }^{6,7}$ Interstitial fluid flow driven by extravascular pressure is thought to be a major form of mechanical stimulation for osteocytes. ${ }^{8-11}$

The small molecules generated by mechanical loading are likely transmitted between cells through gap junctions and between the cell and the extracellular matrix through hemichannels (HCs), which constitute half of all gap junction channels. ${ }^{12} \mathrm{HCs}$, formed by hexameric connexin molecules, ${ }^{13}$ have been demonstrated to be active in osteocytes in response to mechanical stress and are associated with the release of physiologically relevant anabolic molecules, such as prostaglandin E2 $\left(\mathrm{PGE}_{2}\right)$, to the external environment. $^{14,15}$ Prostaglandins released by bone cells are suggested to be skeletal anabolic agents, as they can increase bone mass in animals. ${ }^{16-18}$ As shown in our earlier study, HC activity is adaptively regulated by the magnitude and duration of flow shear stress (FSS). ${ }^{19}$ Our recent study also suggested that impairment of osteocytic HCs has a negative impact on cortical bone structure, strength, and osteocyte viability. ${ }^{20}$

Using a transwell filter system to separate cell bodies from dendritic processes, we demonstrated that dendritic processes sense mechanical stimulation and transmit signals to the cell body to open $\mathrm{HCs}^{21}$ We further found that integrin a5 31 interacts directly with $\mathrm{Cx} 43$ and that this interaction is important for the opening of $\mathrm{HCs}$ on the cell body in response to mechanical loading. ${ }^{22}$ Mechanical stimulation facilitates the opening of $\mathrm{C} \times 43$ $\mathrm{HCs}$, likely through PI3K activation. ${ }^{23}$ In addition, morphological and functional studies suggest that dendritic processes serve as osteocytic mechanosensory sites; ${ }^{21,24,25}$ integrins associated with other extracellular components serve as "tethering elements," which connect the processes with the canalicular wall and amplify mechanical signals. ${ }^{8,26}$ One study showed that integrin $a V \beta 3$, located at the dendritic process, is responsible for the mechanosensory responses of osteocytes. ${ }^{27}$ Nonetheless, it remains unclear how mechanical signals are transmitted from the extended, long dendritic process to the cell body to open Cx43 HCs.

In this study, we unveil a new intracellular mechanotransduction pathway in mechanically sensitive osteocytes via which

${ }^{1}$ Department of Biochemistry and Structural Biology, University of Texas Health Science Center, San Antonio, TX 78229-3900, USA

Correspondence: Jean X. Jiang (jiangj@uthscsa.edu)

Received: 8 February 2020 Revised: 25 September 2020 Accepted: 14 October 2020

Published online: 02 February 2021 
integrin $\mathrm{aV} \beta 3$ at dendritic processes senses shear stress, transmits the signal to the cell body by activating intracellular PI3K-AKT signaling, and activates a5 $\beta 1$. This mechanotransduction leads to the opening of $\mathrm{Cx} 43 \mathrm{HCs}$, which play an essential role in mediating the anabolic function of mechanical loading on bone.

\section{RESULTS}

Activation of integrin $\mathrm{aV} \beta 3$ at dendritic processes opens $\mathrm{HCs}$ on the osteocyte cell body through PI3K-AKT signaling

Integrin aV $\beta 3$ has been implicated as part of a "tethering element" connecting the dendrites of osteocytes to the canaliculi wall. ${ }^{8,25,26,28}$ Immunofluorescence labeling with antibodies specific for integrin $a \mathrm{~V}$ or $\beta 3$ showed that these integrin subunits are located at osteocyte dendritic processes (Fig. 1a). These two integrin subunits are also colocalized, suggesting that they form
aV $\beta 3$ heterodimers. We previously reported that FSS activates integrin a5 $\beta 1$ on the osteocyte cell body and that this activation and direct interaction between $\alpha 5 \beta 1$ and $\mathrm{Cx} 43$ opens $\mathrm{HCs}{ }^{22}$ MLOY4 osteocytic cells were subjected to FSS, and untreated cells were used as controls. Activation of integrin a5 $\beta 1$ was assessed based on increased binding to a GST-FNIII ${ }_{9-11}$ fragment; ${ }^{22,29}$ activation of $\mathrm{aV} \beta 3$ was evaluated by either increased binding to WOW1 Fab ${ }^{30}$ or decreased binding with an inhibitory antibody targeting inactive integrin $\mathrm{aV}^{31}$ (Fig. $1 \mathrm{~b}$ ). Similar to integrin $\mathrm{a} 5 \beta 1$, FSS activated aV $\beta 3$. However, unlike integrin a5 $\beta 1$, integrin aV did not colocalize with $\mathrm{C} \times 43$, which predominately localized on the cell body, as determined by immunofluorescence (Fig. 1c). To evaluate whether $\mathrm{aV} \beta 3$ is the mechanosensor responsible for $\mathrm{HC}$ opening in the cell body, we applied mechanical stress by dropping a liquid on the side of a transwell penetrated by dendritic processes (Fig. 1d, left panel). Mechanical loading by dropping on dendritic a

$\alpha \mathrm{V}$

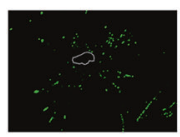

$\beta 3$
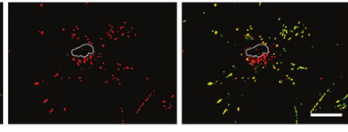

$\alpha \mathrm{V}$

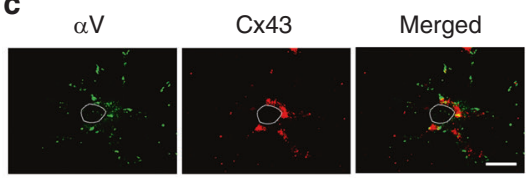

Cx43

e

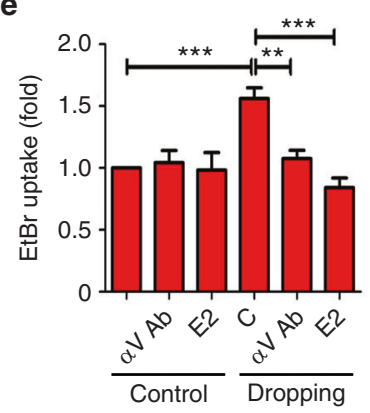

f b GST-FNIII $_{9-11}$ WOW1 Inactive $\alpha \mathrm{V}$
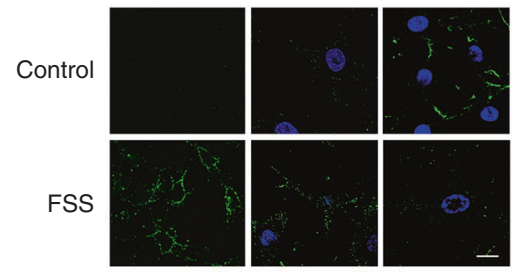

d
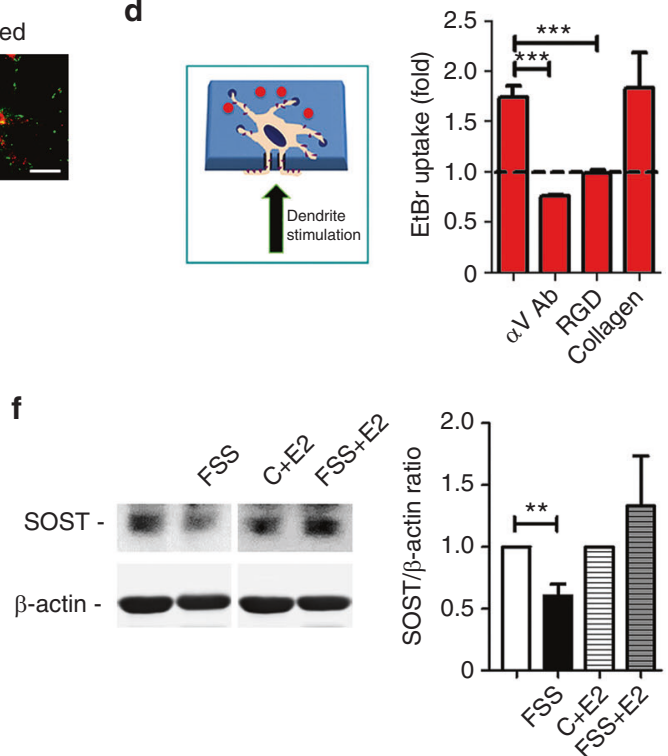

Fig. 1 Integrin $\alpha \mathrm{V} \beta 3$ in osteocytes plays an important role in transmitting mechanical stimulation from dendrites to $\mathrm{HCs}$ located on the cell body. a Integrin $\alpha \mathrm{V}$ colocalizes with $\beta 3$ at the dendritic processes of osteocytes. MLO-Y4 cells were coimmunoprecipitated with an antiintegrin $\alpha \mathrm{V}$ inhibitory antibody on the cell surface and with $\beta 3$ antibodies in permeable cells, followed by incubation with FITC- and rhodamine-conjugated secondary antibodies, respectively. Bar, $10 \mu \mathrm{m}$. b FSS activates integrin $\alpha \mathrm{V} \beta 3$. MLO-Y4 cells were subjected to FSS at 8 dynes per $\mathrm{cm}^{2}$ for 30 min or not treated with FSS and then incubated with the GST-FNIII $\left.\right|_{9-11}$ fragment, immunolabeled with a WOW1 antibody or incubated with an antibody targeting inactive integrin $\alpha \mathrm{V}$, followed by incubation with a FITC-conjugated corresponding secondary antibody. Bar, $10 \mu \mathrm{m}$. c Cell surface-expressed integrin $\alpha \mathrm{V}$ does not localize with Cx43 in osteocytes. MLO-Y4 cells were coimmunoprecipitated with anti-integrin $\alpha \mathrm{V}$ inhibitory and Cx43 antibodies in permeabilized cells, followed by incubation with FITC- and rhodamine-conjugated secondary antibodies, respectively. Bar, $10 \mu \mathrm{m}$. d Activation of integrin $\alpha \mathrm{V}$ by mechanical loading in dendritic processes opens HCs on MLO-Y4 osteocyte cell bodies. MLO-Y4 cells cultured on transwell filter inserts were pretreated with an $\alpha \mathrm{V}$ inhibitory antibody ( $\alpha \mathrm{V}$ Ab), $500 \mu \mathrm{mol} \cdot \mathrm{L}^{-1}$ RGD peptide, or $2.5 \mu \mathrm{g} \cdot \mathrm{mL}^{-1}$ collagen for $15 \mathrm{~min}$. The cells were mechanically stimulated by dropping solution on the dendritic processes (bottom) side of the transwell filter (left panel), after which $\mathrm{EtBr}$ was added, and its uptake was quantified (right panel). The basal level of the dye uptake is indicated by the dashed line. The data are presented as the mean \pm SEM. $n=3$. $* * *, P<0.001$. e Activation of integrin $\alpha \mathrm{V}$ by mechanical loading via liquid dropping opened HCs in IDG-SW3 osteocytes. Differentiated IDG-SW3 osteocytes were pretreated with an $\alpha \mathrm{V}$ inhibitory antibody ( $\alpha \mathrm{VAb}$ ) or a CX43 (E2) antibody for $15 \mathrm{~min}$. The cells were mechanically stimulated by dropping solution, and EtBr uptake was quantified. The data are presented as the mean \pm SEM. $n=3 .{ }^{*}, P<0.05 ;{ }^{* * *}, P<0.001$. $\mathbf{f}$ HCs activated by FSS inhibited SOST expression. IDG-SW3 cells were treated with FSS for $2 \mathrm{~h}$ in the absence or presence of a Cx43(E2) antibody. Four hours after FSS, cell lysates were prepared and immunoblotted with an anti-SOST or anti- $\beta$-actin antibody (left panel), and band intensity was quantified (right panel). The data are presented as the mean \pm SEM. ${ }^{* *}, P<0.01 . n=3$ 
processes in transwell filters increased the uptake of ethidium bromide (EtBr) dye, an indicator of $\mathrm{HC}$ opening, on the cell body. The $\mathrm{HC}$ opening in the cell body was completely attenuated by pretreatment with an integrin $\mathrm{aV}$ inhibitory antibody or an integrin-binding RGD peptide on dendritic processes (Fig. 1d, right panel); this inhibition was not observed with collagen, which cannot bind to aV $\beta 3$.

To further define the role of aV 33 in $\mathrm{Cx} 43 \mathrm{HC}$ activation, we conducted similar studies in differentiated IDG-SW3 osteocytes. Culturing the cells for 9 days in differentiation media resulted in the formation of osteocytes, manifested as increases in the GFP signal $^{32}$ and $\mathrm{Cx} 43$ expression (Fig. S1A). Similar to the phenomenon in MLO-Y4 cells, mechanical loading via liquid dropping opened HCs, which was significantly inhibited by the Cx43(E2) antibody (Fig. S1B). Mechanical loading on dendritic processes opened HCs on the cell body, and this opening was significantly inhibited by the aV activation blocking antibody and the Cx43(E2) antibody (Fig. 1e). Sclerostin (SOST), a Wnt signaling inhibitor, is one of the major proteins expressed by osteocytes ${ }^{33}$ and is thus a negative regulator of bone formation. FSS significantly reduced SOST expression in IDG-SW3 cells, and this inhibition was ablated by the inhibition of $\mathrm{HC}$ opening by the $\mathrm{Cx} 43$ (E2) antibody (Fig. 1f). These data suggest that $\mathrm{Cx} 43 \mathrm{HCs}$ mediate the anabolic function of osteocytes in response to mechanical loading.

To determine how the activation of integrin $\mathrm{aV} \beta 3$ at dendrites opens Cx43 HCs on the osteocyte cell body, we explored the downstream signals activated by aV $\beta 3$. Mechanical loading via liquid dropping at the dendritic processes (left panel) of MLO-Y4 cells opened $\mathrm{HCs}$, as indicated by $\mathrm{EtBr}$ uptake (right panel) (Fig. 2a). Interestingly, the same cells that showed a5 $\beta 1$ integrin activation also exhibited $\mathrm{HC}$ opening; therefore, the integrin a5 activation on the cell body induced by the mechanical loading of dendrites correlated directly with $\mathrm{HC}$ activity (Fig. 2a). These data indicated the possible involvement of integrin a5 $\beta 1$ in the cell body. Activation of the a5 integrin, through its interaction with Cx43, opens $\mathrm{HCs}$ in response to mechanical stimulation. ${ }^{22}$ Inhibition of PI3K by LY294002 (LY), an upstream activating kinase of AKT, significantly blunted the activation of integrin a5 and HC opening induced by integrin aV activation at dendritic processes (Fig. 2a). We then asked whether the activation of intracellular PI3K signaling was sufficient to open HCs. Treatment with IGF-1, a known activator of PI3K signaling, activated AKT, and increased the expression of phosphorylated Akt473; however, LY significantly blocked this activation (Fig. 2b). MLO-Y4 cells were pretreated in the absence or presence of LY or an HC-blocking Cx43(E2) antibody and then incubated with IGF-1. IGF-1 induced $\mathrm{HC}$ opening as indicated by $\mathrm{EtBr}$ dye uptake, and this $\mathrm{HC}$ opening was decreased to basal levels by complete inhibition induced by the $\mathrm{Cx} 43$ (E2) antibody (Fig. 2c). The PI3K inhibitor LY completely blocked the $\mathrm{HC}$ opening induced by IGF-1, suggesting that PI3K activation is responsible for $\mathrm{HC}$ opening.

To determine whether PI3K signaling relies on integrin aV 33 activation induced by mechanical stimulation, we applied mechanical stress, either through liquid dropping on a transwell filter (Fig. 3a) or FSS (Fig. 3b), to MLO-Y4 cells. Activation of PI3KAKT signaling was determined by the ratio of phosphorylated AKT to total AKT (pAKT/total AKT). Increased AKT activation by mechanical loading was significantly inhibited by the integrin $a \mathrm{~V}$ blocking antibody (aV Ab).

To further explore the possible involvement of integrin $\alpha 5 \beta 1$, AKT activation was assessed in cells treated with 30 or $60 \mathrm{nmol} \cdot \mathrm{L}^{-1}$ siRNA targeting a5, $60 \mathrm{nmol} \cdot \mathrm{L}^{-1}$ scrambled (SC) RNA, or vehicle (TA) (Fig. 3c). Integrin a5 siRNA at both concentrations dramatically decreased a5 expression; however, this knockdown had minimal impact on AKT activation induced by FSS. Together, these results suggest that the mechanical stress-induced activation of PI3K-AKT is mediated by integrin aV located at the dendritic processes of osteocytes, and this activation leads to $\mathrm{HC}$ opening.
Integrin a5 $\beta 1$ on the cell body mediates $\mathrm{HC}$ opening by mechanical signals transmitted from osteocyte dendritic processes Our previous studies showed that phosphorylation by AKT is essential for integrin interaction with $\mathrm{C} \times 43$ and $\mathrm{HC}$ opening. ${ }^{23}$ To determine whether integrin $a 5 \beta 1$ is a receiver for signals transmitted by the dendritic process, we targeted a 5 with siRNA (Fig. 4a, left panel). In the transwell assay in which dendritic processes were separated from the cell bodies, mechanical loading via liquid dropping at dendritic processes failed to open $\mathrm{HCs}$ in integrin a5 knockdown cells but not in vehicle (control) or scrambled RNA-treated control cells (Fig. 4b, right panel).

To assess $\mathrm{HC}$ opening and the regulatory effects of a5 integrin in vivo, we generated osteocyte-specific conditional KO (cKO) mice deficient for $\mathrm{C} \times 43$ or integrin a5 by crossing $\mathrm{Cx} 43$ or a5 flox/ flox mice with mice in which Cre was driven by a 10-kb osteocytespecific DMP1 promoter. ${ }^{34}$ DMP-1 is a relatively weak promoter that drives the expression of $\mathrm{Cre}$. To circumvent this issue, an $\mathrm{fl}^{+/-}$ line is typically generated by crossing an flx/flx line with a knockout line. The western blot results showed comparable knockdown of integrin a5 in both $\mathrm{Cre}^{+} ; \mathrm{a}^{\mathrm{fl} / \mathrm{fl} \mathrm{f}}$ and $\mathrm{Cre}^{+} ; \mathrm{a}^{f^{\mathrm{fl} /} /-}$ mice (Fig. S2). HC activation analysis of $\mathrm{Cre}^{+} ; \mathrm{a}^{\mathrm{fl} \times /-}$ mice was conducted using a tibial compression mouse model followed by the Evans blue dye uptake assay. Tibial loading opened HCs in osteocytes of wild-type (WT) mice; however, this activation was attenuated in Cx43-deficient osteocytes in situ (Fig. 4c). Primary osteocytes isolated from a5-deficient cKO mice impaired HC activation in response to FSS (Fig. 4d). Tibial loading data showed that similar to that in Cx43 cKO osteocytes, the opening of HCs was significantly ablated in integrin a5-deficient osteocytes in situ compared to the WT control (Fig. 4e).

The dendritic integrin $a V \beta 3$ is more mechanosensitive than $a 5 \beta 1$ in activating $\mathrm{HCs}$ by mechanical stress

To elucidate the role of $\mathrm{aV} \beta 3$ activation, we injected the $\mathrm{aV}$ inhibitory antibody into WT mice and applied tibial loading (Fig. $5 a)$. Unlike the tibial bone loading protocol to determine anabolic function, tibial bone loading differed here in that the bone was mechanically loaded only once, and no woven bone was detected. Woven bone formation was not detected even under the identical loading magnitude for 10 days (Fig. S3a and b). After 10 days of tibial loading, the anabolic response was evident, with a significant increase in bone mineral density (BMD) being observed in WT mice (Fig. S3C). The distribution of the antibody signals appeared striated around the osteocyte lacuna, suggesting canaliculi distribution (Fig. 5b, image amplification in the right panel, arrowheads), and this observation was consistent with the presence of $\mathrm{aV}$ in osteocyte dendrites. As expected, tibial compression increased Evans blue uptake when compared with that of the contralateral leg (Fig. 5c, left panel). Application of the $\mathrm{aV}$ inhibitory antibody significantly inhibited the $\mathrm{HC}$ opening induced by tibial compression (Fig. 5c, right panel).

We designed an experiment to observe differences in the mechanosensitivities of $\operatorname{aV} \beta 3$ and $\alpha 5 \beta 1$ to activate HCs. FSS at 8 dynes per $\mathrm{cm}^{2}$ induced $\mathrm{HC}$ opening, as indicated by EtBr uptake, and this opening was blocked by the $\mathrm{aV}$ inhibitory antibody ( $\mathrm{aV}$ Ab) (Fig. 6a, upper left panel). However, the HC opening induced by 16 dynes per $\mathrm{cm}^{2}$ FSS was not inhibited by the aV antibody (Fig. 6a, upper right panel). The specificity of $\mathrm{Cx} 43 \mathrm{HC}$ activity was validated using an HC-blocking Cx43(E2) antibody, and the extent of dye uptake was quantified (Fig. $6 a$, lower panel). These data suggest that the mechanotransduction pathway initiated by aV $\beta 3$ at the dendrites can be activated at low FSS levels, which fail to activate integrin a5 directly on the cell body. However, a high FSS level directly activates a5, which may bypass the intracellular transmission pathway to open HCs. Due to differences in their sensitivities to mechanical stimulation, integrin molecules at different locations within osteocytes act coordinately to regulate biological functions in response to mechanical stresses of differing 
a

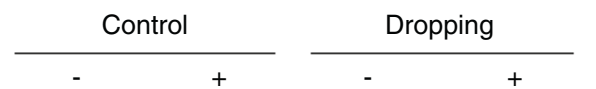

LY
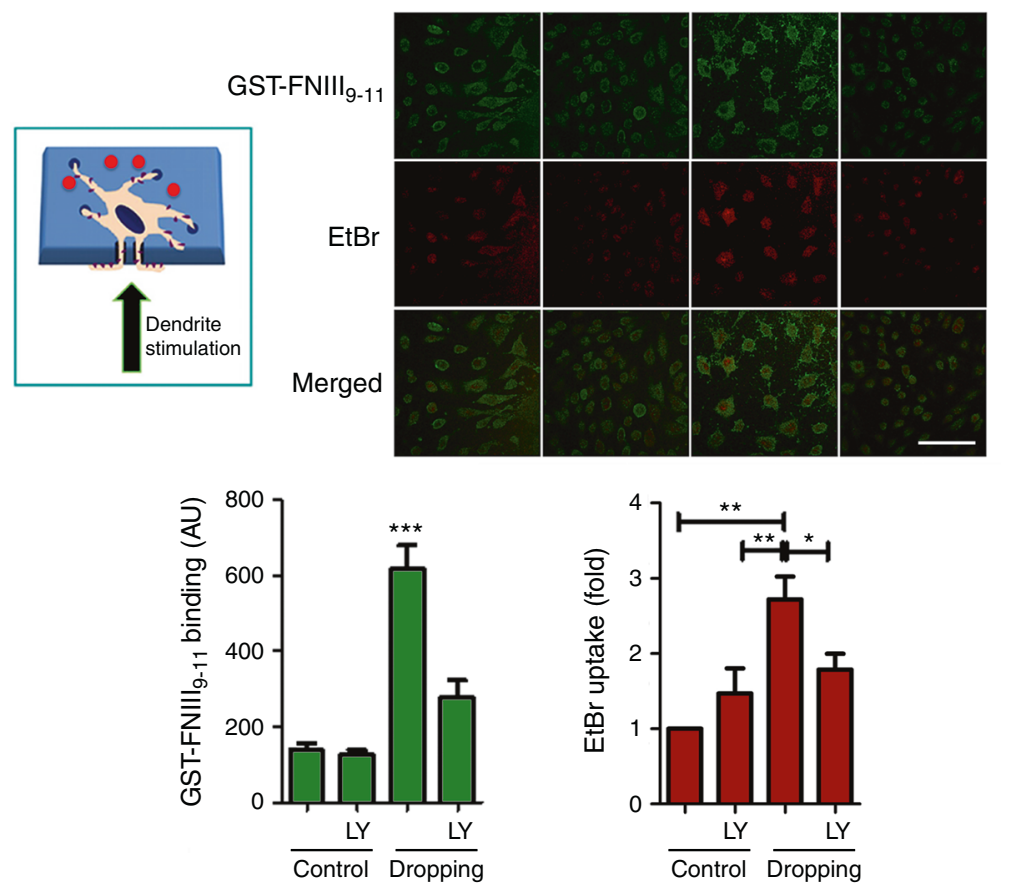

b

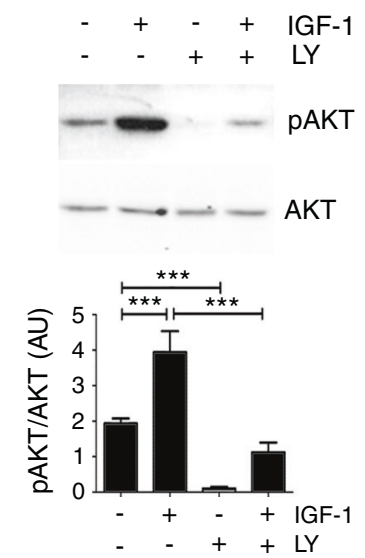

C

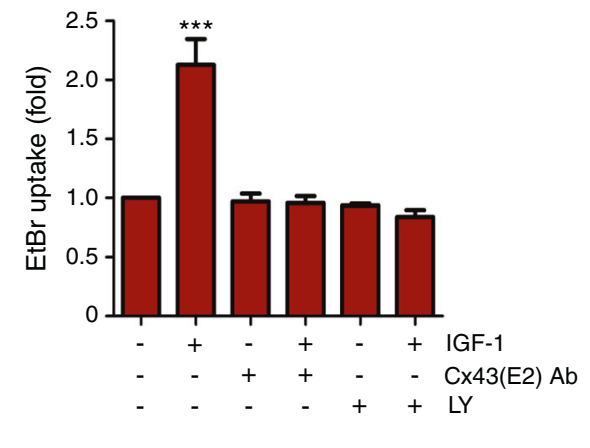

Fig. 2 Activation of PI3K by mechanical loading is essential for $\mathrm{HC}$ opening. a Inhibition of PI3K signaling prevents the activation of $\alpha 5 \beta 1$ and the opening of HCs by mechanical loading. MLO-Y4 cells preincubated with or without $10 \mu \mathrm{mol} \cdot \mathrm{L}^{-1} \mathrm{LY} 294002$ (LY) for 15 min were subjected to mechanical loading by liquid dropping with $50 \mu \mathrm{mol} \cdot \mathrm{L}^{-1} \mathrm{EtBr}$ solution to the dendritic process side of the transwell filter (upper left panel). The cell body side of the transwell filter was then incubated with the GST-FNIII ${ }_{9-11}$ fragment. The confocal fluorescence images were taken; green fluorescence indicates binding of the GST-FNIII ${ }_{9-11}$ fragment, and red fluorescence indicates the uptake of EtBr (upper right panel). The extents of $\alpha 5$ activation (lower left panel) and HC opening (lower right panel) were determined based on GST-FNIII ${ }_{9-11}$ binding and EtBr uptake, respectively. Bar, $100 \mu \mathrm{m}$. Cells under dropping versus all other treatments, ${ }^{*}, P<0.05 ;{ }^{* *}, P<0.01 ;{ }^{* * *}, P<0.001$. b Activation of PI3KAKT by IGF-1 in osteocytes. MLO-Y4 cells were pretreated with or without LY and then incubated with $5 \mathrm{ng} \cdot \mathrm{mL}^{-1}$ IGF-1 for $30 \mathrm{~min}$. Cell lysates were immunoblotted with an anti-phospho-AKT (Ser473) (pAKT) or total AKT antibody. The band intensity and the ratio of phosphorylated to total AKT were quantified (lower panel). c The opening of HCs requires PI3K activation. MLO-Y4 cells were pretreated with or without LY or a Cx43(E2) antibody for $15 \mathrm{~min}$ and then incubated with $5 \mathrm{ng} \cdot \mathrm{mL}^{-1}$ IGF-1. HC activity was then measured by EtBr dye uptake. All data are presented as the mean \pm SEM. $n=3$. Cells treated with only IGF-1 versus all other treatments and control, ${ }^{* *}, P<0.001$

magnitudes. Together, our data from in vitro cell studies and in vivo mouse transgenic models with tibial loading showed that the activation of dendritic aV $\beta 3$ by mechanical loading transmits the signals to a5 $\beta 1$ on the cell body, leading to $\mathrm{HC}$ opening.

\section{DISCUSSION}

Osteocytes with extensive, long dendritic processes and a fluidfilled lacunae-canaliculi system are well positioned in the bone to sense mechanical stress and play a critical role in skeletal adaptation and anabolic responses to loading. ${ }^{8}$ In this study, we show that integrin $\mathrm{aV} \beta 3$, located at the dendritic processes of osteocytes, serves as a distal mechanical sensor of osteocytes. As illustrated in Fig. $6 \mathrm{~b}$, activation of integrin aV transmits signals to the cell body to open HCs. This intracellular mechanotransduction pathway is mediated through the activation of intracellular PI3KAKT signaling. The transmission of the signals to the cell body activates integrin $\alpha 5 \beta 1$ and consequently opens $\mathrm{Cx} 43 \mathrm{HCs}$. We 
a
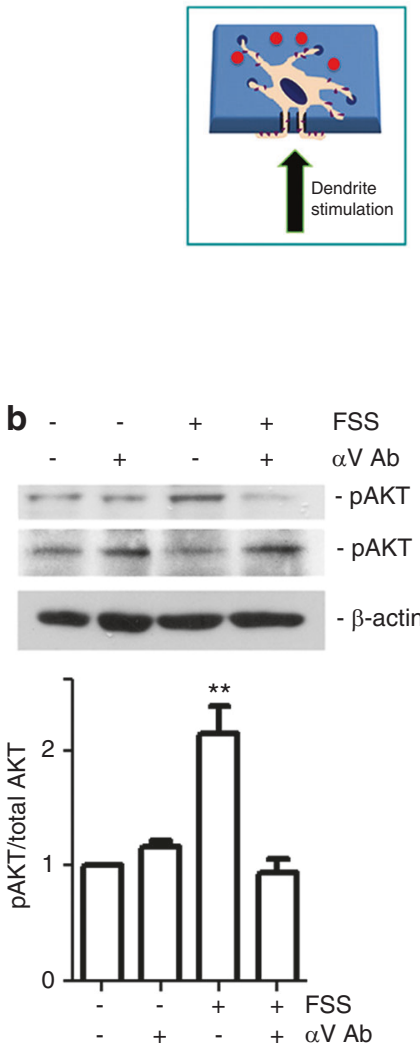

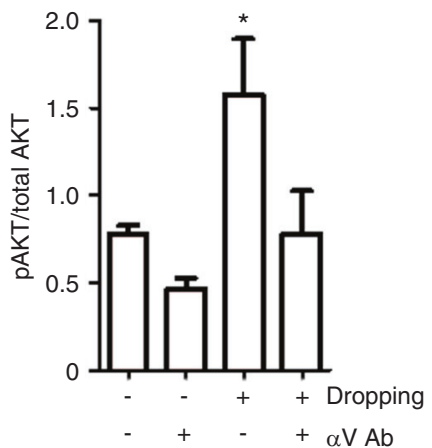

C

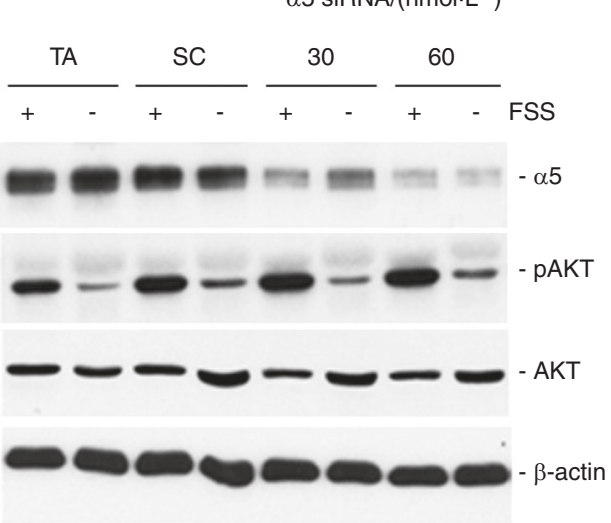

Fig. 3 Integrin $\alpha \mathrm{V}$ is required for PI3K-AKT activation induced by mechanical stress. a Inhibition of integrin $\alpha \mathrm{V}$ prevents AKT activation induced by mechanical dropping on dendritic processes. MLO-Y4 cells cultured on transwell filter inserts were preincubated with an antibody blocking $\alpha \mathrm{V}$ activation $(\alpha \mathrm{V} \mathrm{Ab})$ for $20 \mathrm{~min}$ and mechanically stimulated by solution dropping on the dendritic process side of the transwell filter. The fixed cells were immunolabeled with an anti-phospho-AKT (Ser473) (pAKT) or total AKT antibody. The fluorescence intensities of pAKT and total AKT were quantified, and their ratio was calculated. Cells stimulated by dropping only versus all other treatments, ${ }^{*}, P<0.05$. $\mathbf{b}$ Inhibition of integrin $\alpha \mathrm{V}$ prevents AKT activation induced by FSS. MLO-Y4 cells were subjected to FSS for 30 min, and cell lysates were immunoblotted with an anti-pAKT or total AKT antibody (upper panel). The intensities of the protein bands were quantified, and the ratio was calculated and normalized to resting conditions (lower panel). Cells stimulated by FSS only versus all other treatments, ${ }^{* *}, P<0.01$. The data are presented as the mean \pm SEM. $n=3$. c Knocking down integrin $\alpha 5$ has no effect on AKT activation induced by FSS. MLO-Y4 cells were pretreated with 30 or $60 \mathrm{nmol} \cdot \mathrm{L}^{-1} \propto 5$ siRNA, scrambled RNA (SC) or vehicle control (TA) for $48 \mathrm{~h}$ and then subjected to FSS for 30 min. Cell lysates were immunoblotted with an anti- $\alpha 5$, pAKT, AKT, or $\beta$-actin antibody

previously showed that $\alpha 5 \beta 1$ on the cell body regulates $\mathrm{HC}$ opening through its phosphorylation by AKT and direct interaction with $\mathrm{C} \times 43 .^{22}$ For the first time, we herein identify an intracellular mechanotransmission mechanism, initiating from mechanosensitive dendritic integrin molecules, that leads to the activation of intracellular signaling molecules and integrin molecules on the cell body, ultimately resulting in $\mathrm{HC}$ activation. We demonstrated this mechanotransduction pathway utilizing both cellular techniques in vitro and transgenic and mechanical loading models in vivo.

Osteocytes are highly responsive to dynamic or steady forms of fluid FSS, and the aV $\beta 3$ and a5 $\beta 1$ integrins in osteocytes can be activated after both types of mechanical stimulation. ${ }^{22,27,35,36}$ While different types of FSS exist, we used steady fluid flow in this study; osteocytes are reportedly more responsive to steady fluid flow than to oscillatory fluid flow, as indicated by the induction of more intracellular $\mathrm{Ca}^{2+}$ peaks with higher magnitudes. ${ }^{37}$ In our previous study, we compared steady and pulsatile flows and showed that their effects on Cx43 gap junction channels and HCs were comparable. ${ }^{19,38}$ Mechanical loading at physiological levels is shown to decrease sclerostin levels and promote anabolic function in IDG-SW3 osteocytes. ${ }^{39}$ We herein show that the inhibition of $\mathrm{Cx} 43 \mathrm{HC}$ activation with the Cx43(E2) antibody attenuated the SOST reduction in response to fluid shear stress, implicating the anabolic effect of functional Cx43 HCs during mechanical loading. We previously showed that $\mathrm{Cx} 43 \mathrm{HCs}$ activated by FSS serve as portals for the release of $\mathrm{PGE}_{2},{ }_{14}$ which has been shown to function in an autocrine fashion to inhibit SOST expression. ${ }^{40}$ Therefore, decreased SOST expression likely results from the autocrine function of $\mathrm{PGE}_{2}$ or other factors being released through the opening of $\mathrm{Cx} 43 \mathrm{HCs}$.

Interestingly, although high levels of mechanical loading can directly activate integrin a5 and open $\mathrm{HCs}$, as shown in the current study with FSS as well as in previous studies on liquid dropping, ${ }^{21}$ this activation appears to originate primarily from integrin $\mathrm{aV}$ at dendritic processes under low FSS conditions. Compared to integrin $\mathrm{a} 5$, dendritic integrin $\mathrm{aV}$ is a more sensitive mechanosensor that can be activated by a lower level of mechanical stress on the cell body. This finding may be attributed to the fact that integrin aV is part of a "tethering" element, which attaches the dendritic processes of osteocytes to the canaliculi wall. According to the strain amplification model proposed by Weinbaum and colleagues, $8,25,26,28$ the force experienced at the "tethering" site is of a higher magnitude than that experienced without attachment. Because of this strain magnification, a low level of mechanical stimulation can be readily sensed and amplified by integrin aV. 
a

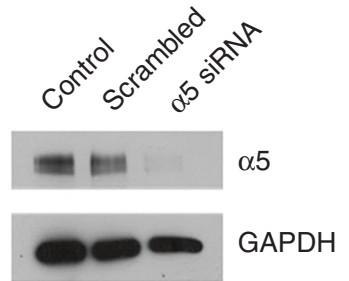

b

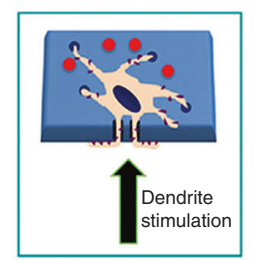

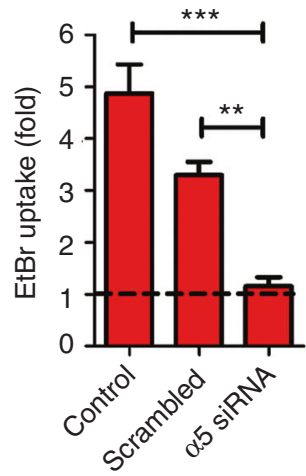

C

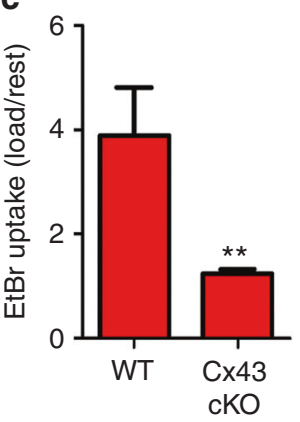

d

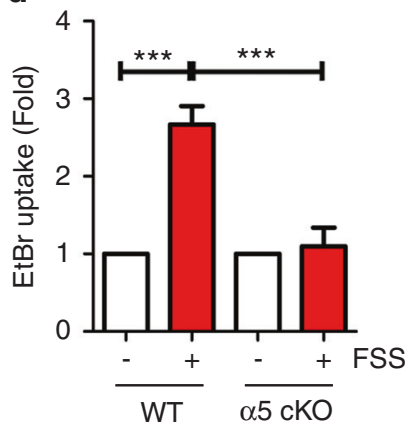

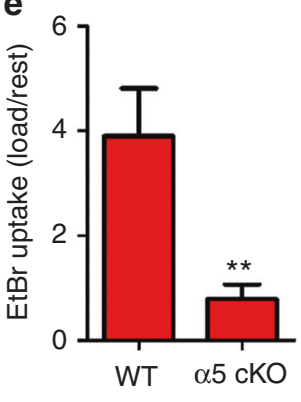

Fig. 4 Mechanical stimuli at osteocyte dendritic processes are transmitted and open HCs through integrin $\alpha 5$. a Knockdown of integrin $\alpha 5$ expression by siRNA. MLO-Y4 cells were treated with $\alpha 5$ siRNA, scrambled RNA, or vehicle control for $48 \mathrm{~h}$. Cell lysates were immunoblotted with an anti- $\alpha 5$ or GAPDH antibody. b Integrin $\alpha 5$ siRNA inhibits HC opening induced by mechanical loading on dendritic processes. Cells pretreated with $\alpha 5$ siRNA, scrambled RNA or a nontreatment control were mechanically stimulated by dropping $50 \mu \mathrm{mol} \cdot \mathrm{L}^{-1} \mathrm{EtBr}$ solution on the dendritic process (bottom) side of the filter (left panel). The extent of EtBr uptake was quantified on the cell body side of the transwell filter. The basal uptake is indicated by the dashed line. $\alpha 5$ siRNA versus the control and scrambled RNA-treated group. All data are presented as the mean \pm SEM. $n=3$. ${ }^{* *}, P<0.001$, and ${ }^{* *}, P<0.01$. c Deficiency of osteocytic Cx43 in cKO mice attenuated the opening of Cx43 HCs by mechanical loading in situ. Tibial compression was conducted in WT and Cx43 cKO mice, and Evans blue was intravenously (IV) injected. After $2 \mathrm{~h}$, the mice were perfused with PBS, and bone tissues were isolated. Evans blue uptake was evaluated by fluorescence signals, and the intensity of dye uptake in osteocytes was quantified by ImageJ. The data are presented as the mean \pm SEM. $n=3$. ${ }^{* *}, P<0.01$. d Deficiency of integrin $\alpha 5$ in osteocytes isolated from integrin $\alpha 5$ CKO mice attenuated the activation of Cx43 HCs by FSS. Primary osteocytes were isolated from 3-week-old WT and CKO mice and subjected to FSS for $15 \mathrm{~min}$. EtBr uptake was conducted and quantified. The data are presented as the mean \pm SEM. $n=3$. ${ }^{* * *}, P<0.001$. e Deficiency of osteocytic integrin $\alpha 5$ in cKO mice attenuated the activation of Cx43 HCs by mechanical loading in situ. Tibial compression was conducted in WT and integrin $\alpha 5 \mathrm{cKO}$ mice, and Evans blue was IV injected. Evans blue uptake was evaluated by fluorescence (left panel), and the intensity of dye uptake in osteocytes was quantified by ImageJ (right panel). The data are presented as the mean \pm SEM. $n=3 .{ }^{* *}, P<0.01$

Therefore, mechanical signals must be transmitted by intracellular signals from dendritic processes to the cell body to activate integrin a5 and open HCs. Conversely, integrin a5 on the cell body can be directly activated by higher levels of mechanical stimulation. Unlike the dendritic integrin $\mathrm{aV}$, the association of integrin a5 with its substrate, fibronectin, is not essential for $\mathrm{HC}$ opening, as we showed in our previous study. ${ }^{22}$ This evidence implies that an intracellular, not an extracellular, signal is responsible for the activation of integrin a5 and consequently for the opening of $\mathrm{Cx} 43 \mathrm{HCs}$ under low mechanical load conditions.

$\mathrm{PI3K}$ is activated in response to mechanical loading in osteocytes, ${ }^{22}$ and integrin $\mathrm{aV}$ is reported to activate PI3K by binding to focal adhesion kinase. ${ }^{41}$ Since the dendritic integrin aV 33 is an initial mechanosensor in osteocytes, we investigated whether PI3K activation depends upon this integrin. Our data showed that PI3K was activated upon mechanical loading and that this activation could be blocked by integrin aV inactivation, suggesting that the activation of intracellular PI3K signaling relies on aV activation in response to mechanical loading. Very interestingly, we showed that IGF-1 also opened HCs, and this effect was mediated by the activation of PI3K signaling given that the inhibition of PI3K completely abolished the effect of
IGF-1 on HC opening. These results support the notion that PI3K activation is sufficient to open HCs regardless of whether the signals are initiated by mechanical loading or other factors, such as IGF-1.

Knocking down integrin a5 does not affect $\mathrm{PI} 3 \mathrm{~K}$, indicating that contrary to $\mathrm{aV}, \mathrm{PI} 3 \mathrm{~K}$ signaling appears to be an upstream responsive element that bears the force-induced signal and transmits it to integrin a5 $\beta 1$, leading to its conformational activation. AKT is activated by PI3K signaling and is used as an indicator of PI3K activation. AKT has also been shown to be activated in response to mechanical loading in osteocytes. ${ }^{42,43}$ Our recent studies showed that FSS-activated AKT directly phosphorylates $\mathrm{Cx} 43$ and integrin a5 and that the phosphorylation of $\mathrm{Cx} 43$, in particular, plays a predominant role in its interaction with $a_{5} ;^{23}$ this interaction on the cell body is essential for $\mathrm{HC}$ opening. ${ }^{23}$ Therefore, AKT is likely the effector of activated signaling that regulates $\mathrm{HC}$ opening, and $\mathrm{HC}$ opening leads to the release of molecules that promote bone cell responses to loading, resulting in an anabolic environment.

In addition to osteocyte cell models with mechanical loading, either with FSS or liquid dropping, we validated a mechanotransduction mechanism in vivo using two osteocyte-specific mouse cKO models with mechanical stimulation via axial 


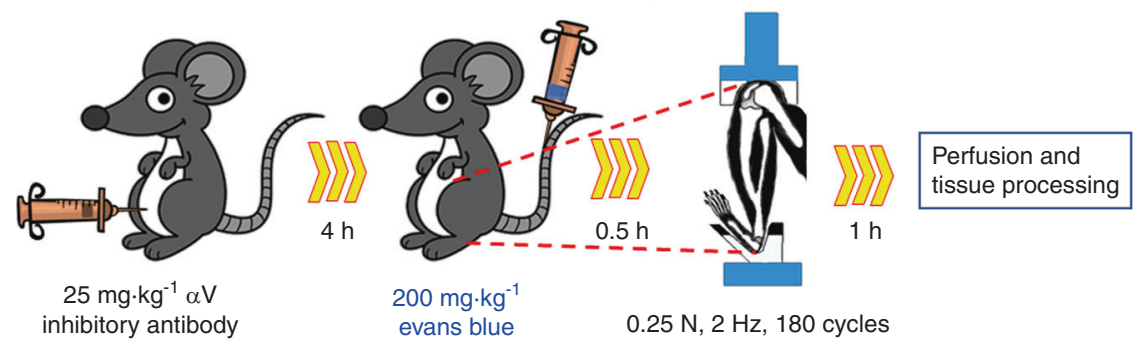

b

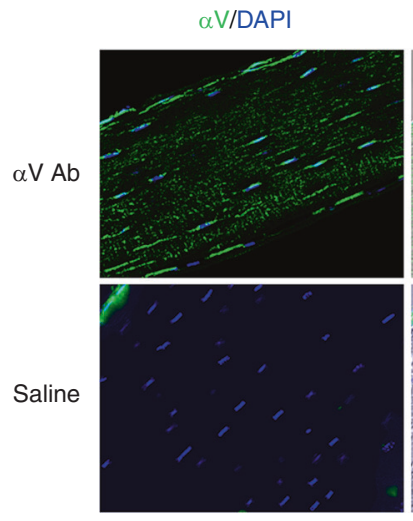

$\alpha$ V/DAPI/Phase

C

EB/DAPI
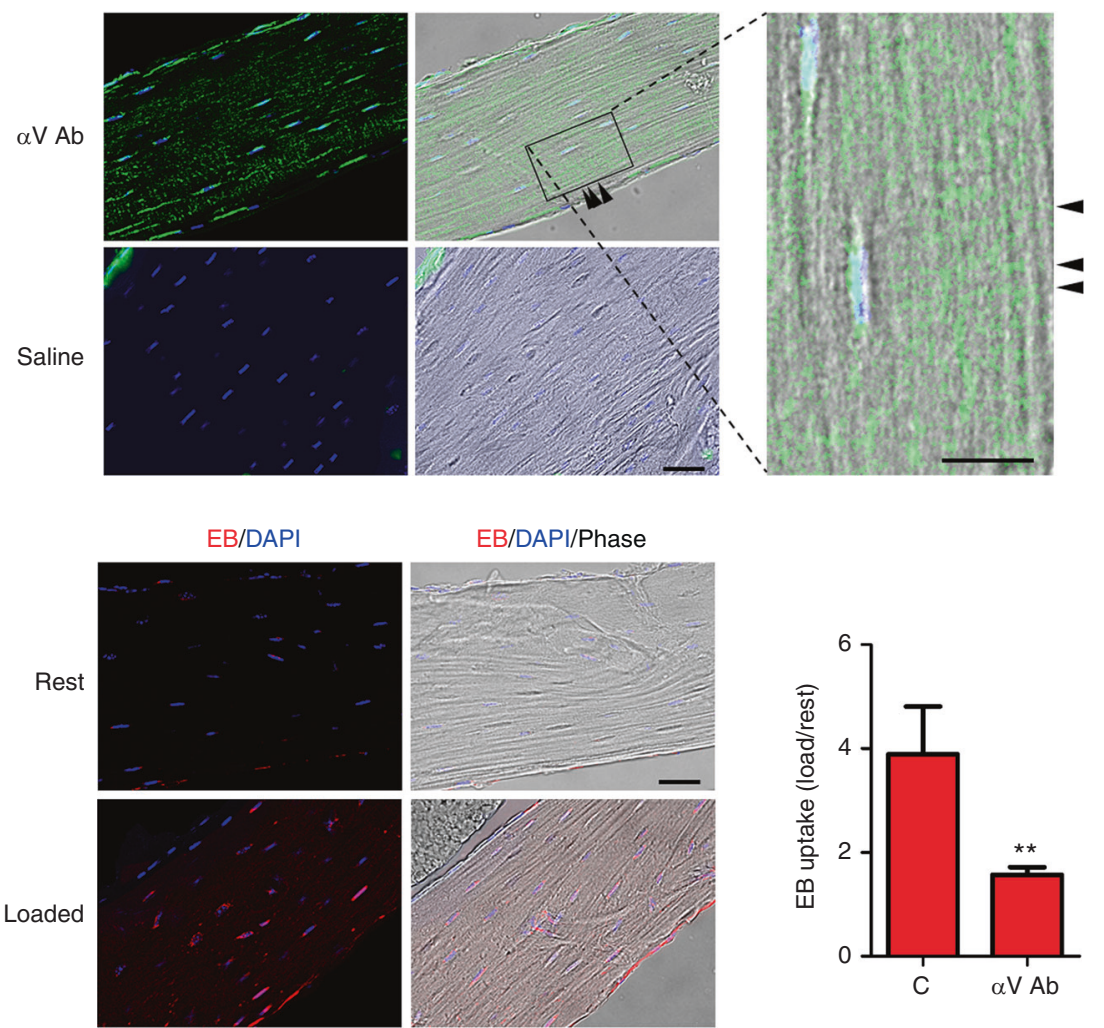

EB/DAPI/Phase
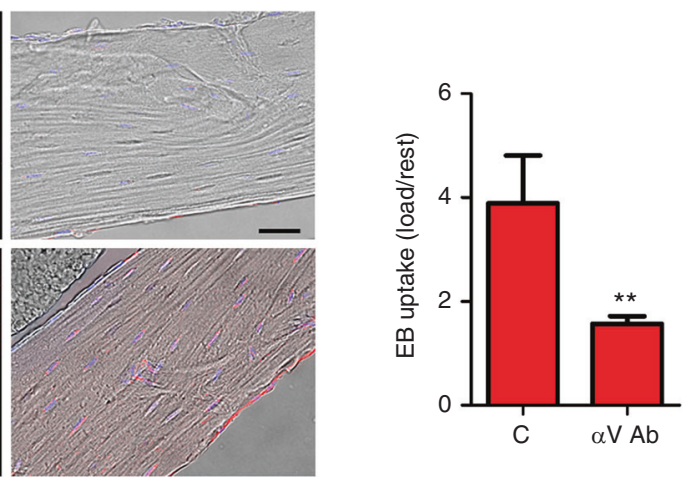

Fig. 5 Integrin $\alpha \mathrm{V}$ activation is required for osteocyte $\mathrm{HC}$ opening in vivo. a Schematic model of tibial compression in mice treated with an anti- $\alpha \mathrm{V}$ inhibitory antibody. The antibody was IP injected $4 \mathrm{~h}$ before Evans Blue was IV injected. Tibial compression was conducted in WT mice injected with or without an antibody. b The anti- $\alpha \mathrm{V}$ inhibitory antibody distribution in the bone was traced using Alexa 488-conjugated antiArmenian hamster IgG. Bar, $50 \mu \mathrm{m}$. The $4.5 \mathrm{X}$ amplification of the image shows the reactivity distribution striated around the osteocyte dendrites (right panel, arrowheads). Bar, $25 \mu \mathrm{m}$. c Inhibition of osteocyte HC opening by an anti- $\alpha \mathrm{V}$ inhibitory antibody. Evans blue uptake was evaluated by fluorescence signals (left panel). Bar, $50 \mu \mathrm{m}$. The intensity of dye uptake in osteocytes was quantified by ImageJ (right panel). The data are presented as the mean \pm SEM. $n=3 .{ }^{*}, P<0.01$

compression on tibias. Tibial compression opened HCs in only WT osteocytes and not in those of Cx43 cKO mice with osteocytespecific Cx43 deficiency, which suggests that the Cx43 HCs in osteocytes are responsive to mechanical loading. We also showed the impairment of HCs in a5-deficient osteocytes, which occurred for both isolated primary osteocytes and osteocytes in situ. Interestingly, when WT mice were injected with an aV inhibitory antibody and subjected to tibial loading, the inhibition of HCs in osteocytes was significantly but incompletely inhibited compared to that of the untreated control. This result may have been due to the partial effectiveness of the antibody. Alternatively, it may also be explained by the aforementioned mechanism related to the differences between $\mathrm{aV} \beta 3$ on dendrites and $a_{5} \beta 1$ on the cell body. High levels of mechanical loading may, at some threshold, directly activate $\alpha 5 \beta 1$, which can then bypass the requirement for activation through the $\operatorname{aV} \beta 3$ pathway.
This study focused on the mechanism of mechanotransduction from osteocyte dendritic processes to the cell body via the interplay of two types of integrins and $\mathrm{C} \times 43 \mathrm{HCs}$. Previous studies have reported the results of $\mathrm{C} \times 43$ knockout mouse models. When Cx43 was deleted in mature osteoblasts, endocortical bone formation was attenuated in response to four-point tibial bending. ${ }^{44}$ In addition, in three other studies, osteoblast precursors, mature osteoblasts, and osteocytes with Cx43 deletion all showed enhanced periosteal formation, ${ }^{45-47}$ and one study showed attenuated endocortical formation. ${ }^{48}$ In Cx43 knockout models, both gap junctions and HCs are compromised, not just $\mathrm{HCs}$, and gap junctions reportedly play significantly different roles from $\mathrm{HCs}$, with $\mathrm{HCs}$ being highly responsive to mechanical loading in osteocytes. Furthermore, whether other proteins and pathways are upregulated to potentially compensate for the deletion of Cx43 remains unknown, and a compensatory mechanism has 


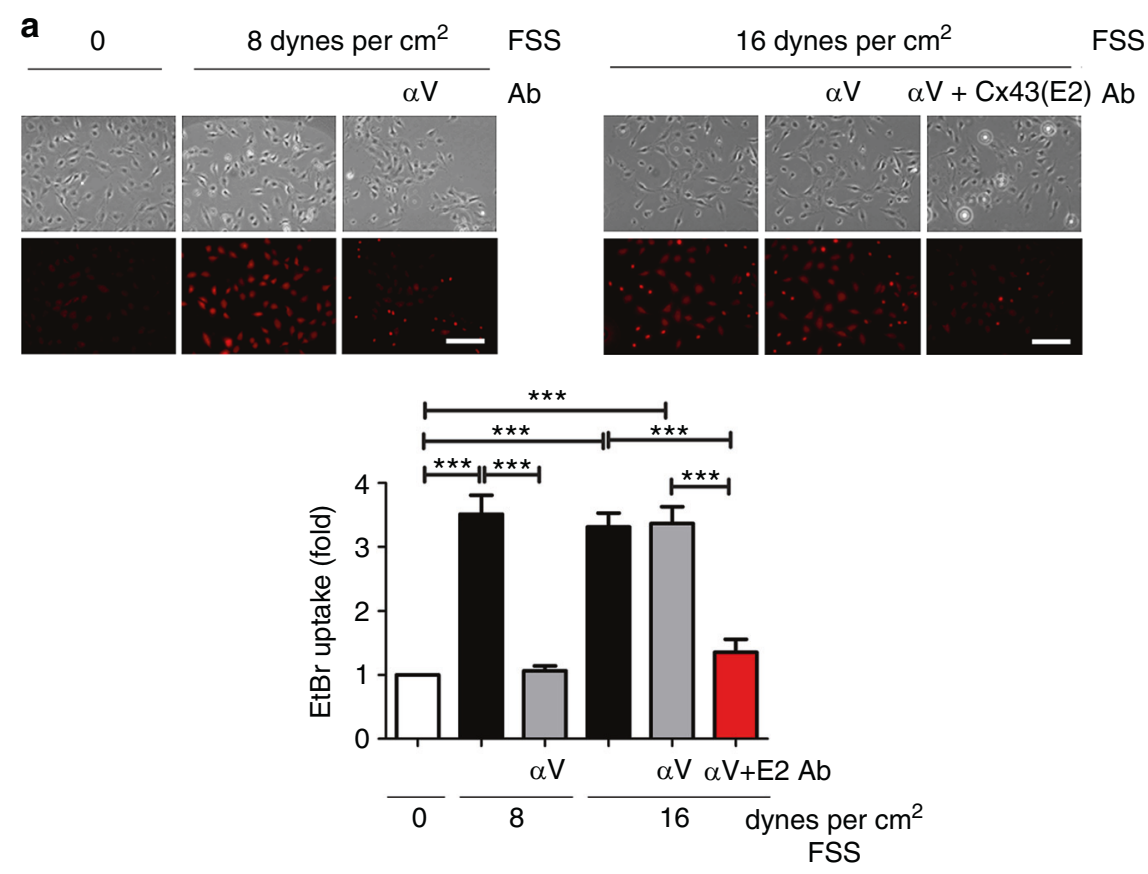

b

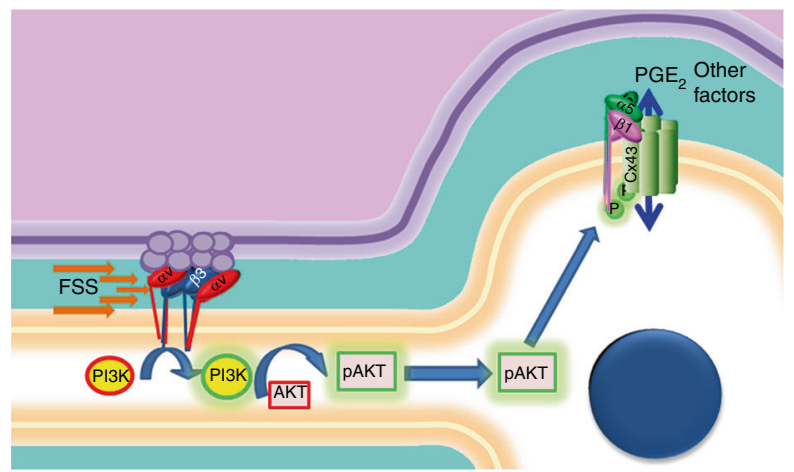

Fig. 6 Integrin $\alpha \mathrm{V}$ activation is required for $\mathrm{HC}$ opening at low but not high FSS levels. a Inhibition of integrin $\alpha \mathrm{V}$ activation prevents $\mathrm{HC}$ opening at low but not high FSS levels. MLO-Y4 cells were pretreated with an antibody blocking $\alpha \mathrm{V}$ activation ( $\alpha \mathrm{V}$ Ab) or an HC-blocking Cx43 (E2) antibody and then subjected to treatment with 8 dynes per $\mathrm{cm}^{2}$ FSS (upper, left panel), 16 dynes per $\mathrm{cm}^{2}$ FSS (upper, right panel), left untreated, or treated with a static control; EtBr dye was added. The degree of dye uptake was quantified (lower panel). Bar, $100 \mu \mathrm{m}$. The data are presented as the mean \pm SEM. $n=3$. ${ }^{* *}, P<0.001$. b Mechanotransduction occurs in osteocytes through the functional interplay of integrins and $\mathrm{C} \times 43 \mathrm{HCs}$. Integrin $\alpha \mathrm{V} \beta 3$ located at the dendrites of osteocytes as part of tethering elements facilitates the attachment of osteocytes to the canalicular wall, and this unique arrangement amplifies the magnitude of FSS experienced by osteocytes. ${ }^{8,26}$ FSS through the lacunae-canaliculi network induces the activation of $\alpha \mathrm{V} \beta 3$, which leads to the activation of intracellular PI3K and subsequent AKT activation. The activation of AKT results in the conformational activation of integrin $\alpha 5 \beta 1$. The phosphorylation of Cx43 by AKT and direct interaction between $\mathrm{Cx} 43$ and $\alpha 5 \beta 1$ open $\mathrm{HCs}^{23}$ which allows the release of small molecule bone factors, such as $\mathrm{PGE}_{2}$, which are important for bone formation and remodeling

been reported in other gene knockout models. Other channels are also reported to be involved in the mechanotransduction of osteocytes, such as the P2X7-pannexin1 channel and the recently identified Piezo1 channel. ${ }^{49-51}$

We found that upon exposure to mechanical loading of various magnitudes, osteocytes responded differently, and this difference could be partially explained by the sensitivity of mechanical sensors and integrins on the osteocyte cell surface. Our data showed that low levels of mechanical stress, which were insufficient to activate a5 $\beta 1$ integrins, activated av $\beta 3$ integrins located in dendrites. Due to the unique anatomical structure of dendritic processes, the shear stress level is substantially magnified, possibly via the "tethering element", which attaches osteocyte dendrites to the canaliculi wall. A higher level of shear stress, however, could directly activate $\alpha 5 \beta 1$ on the osteocyte cell body and open HCs. Unlike osteocytes in vivo, no canaliculi are present, and the binding of integrin av $\beta 3$ to the matrix can therefore amplify the mechanical stimulation. We previously showed that in contrast to av $\beta 3$ activation, that of $a 5 \beta 1$ in osteocytes is independent of its association with the extracellular matrix. ${ }^{22}$ Based on this evidence, osteocytes, integrins, and HCs appear to behave similarly in situ and in cell culture in response to mechanical loading. In our previous studies, we applied FSS and fluid dropping to osteocytes and found that integrins and $\mathrm{HCs}$, as well as PI3K/AKT signaling, were similarly activated by these two forms of mechanical loading. ${ }^{21,22}$ Nevertheless, because of technical limitations, we cannot exclude other differences induced by different forms of mechanical stimulation. Some study limitations include the impact of matrix properties, duration, and frequency of mechanical stimulation. To mitigate the variation between cellular environments in vitro, we used a transwell system that allows separation of the osteocyte cell body and 
dendritic processes. The fluid dropping approach permitted us to specifically apply mechanical stimulation to the dendritic processes of osteocytes. ${ }^{21}$ Our data suggest that PI3K/AKT is a major signaling pathway by which $\mathrm{Cx} 43 \mathrm{HCs}$ are opened, and inhibition of this pathway attenuates the effect of integrins on $\mathrm{Cx} 43 \mathrm{HC}$ activation. However, we cannot exclude the involvement of other signaling pathway(s), especially those activated by mechanical loading in bone remodeling. It is well acknowledged that crosstalk exists between most major signal transduction pathways, ${ }^{52}$ with examples including the PI3K/AKT, $\mathrm{Ca}^{2+}$, and PKA pathways, all of which are activated by mechanical loading.

Together, the results of this study establish the critical link between intracellular mechanotransduction pathways and their effects on the anabolic activity of bone through the functional interplay of integrin subtypes, cell signaling molecules, and connexin channels. Elucidation of the functional interplay between integrins and connexin channels will substantially advance mechanobiology in general. Moreover, this discovery may lead to therapeutics involving the specific targeting of $\mathrm{HCs}$ for bone loss due to not only bone diseases such as osteoporosis but also aging and space flight or immobilization, which result in a lack of mechanical loading.

\section{MATERIALS AND METHODS}

Cell culture and reagents

MLO-Y4 osteocytic cells derived from murine long bones were cultured on rat tail collagen type l-coated surfaces and grown in amodified essential medium (a-MEM) supplemented with $2.5 \%$ fetal bovine serum (FBS) and $2.5 \%$ bovine calf serum (BCS) as described previously. ${ }^{53}$ Preosteocyte IDG-SW3 cells were cultured in a-MEM supplemented with $5 \mathrm{ng} \cdot \mathrm{mL}^{-1}$ IFNy at $5 \% \mathrm{CO}_{2}$ and $33^{\circ} \mathrm{C}$. After reaching confluence, they were cultured in differentiation medium (a-MEM supplemented with 10\% FBS, 1\% penicillinstreptomycin, $50 \mu \mathrm{g} \cdot \mathrm{mL}^{-1}$ ascorbic acid and $4 \mathrm{mmol} \cdot \mathrm{L}^{-1}$ $\beta$-glycerophosphate) for 9 days to promote differentiation into osteocytes. ${ }^{32}$ MLO-Y4 cells were also plated on rehydrated $(250 \mu \mathrm{L}$ of media for $30 \mathrm{~min}$ ) transwell filter inserts (Biocoat ${ }^{\circledast}$ Cell Culture Inserts, $1.0 \mu \mathrm{m}$ pores, BD Biosciences, Bedford, MA). The transwell occupancy rate was $\sim 80 \%-85 \%$, and the cells were $\sim 50 \%$ confluent. The cells were then either subjected to mechanical stimulation or processed for immunostaining. The $\mathrm{Cx} 43(\mathrm{E} 2)$ antibody was generated and affinity purified as previously described. ${ }^{19}$ An antibody targeting integrin a5 (CD49e) (R\&D Systems, MN), a mouse anti- $\beta 3$ antibody (Developmental Studies Hybridoma Bank, lowa City, IA), integrin aV clone H9.2B8 (BD Bioscience, NJ), and tripeptide RGD (Biomol, PA) were used in this study. WOW1 was generously provided by Dr. Sanford Shattil (University of California at San Diego), and a glutathione Stransferase (GST)-tagged portion of fibronectin protein 9-11 (GSTFNIII $_{9-11}$ ) was generously provided by Dr. Martin Schwartz (Yale University).

Isolation of primary osteocytes from long bone tissues of a5 cKO mice

The protocol for preparing primary osteocytes from bone pieces was modified from a previously published method. ${ }^{54}$ Briefly, long bones from 3- to 4-week-old mice were dissected, and soft tissues and bone marrow were removed. The bones were cut into pieces $\sim 2 \mathrm{~mm}$ in length and digested by alternate usage of collagenase type I and ethylenediaminetetraacetic acid (EDTA) on a rotating shaker in a $\mathrm{CO}_{2}$ incubator at $37^{\circ} \mathrm{C}$. After multiple treatments with collagenase type I and EDTA to remove other bone cells, the bone pieces were plated on a collagen-coated dish in a-MEM supplemented with $2.5 \%$ FBS and $2.5 \%$ BCS and left untouched for 9 days. The osteocytes from the bone pieces were removed by trypsinization and seeded on collagen-coated glass to apply FSS in a-MEM supplemented with $2.5 \%$ FBS and $2.5 \%$ BCS.
Immunofluorescence labeling, integrin activation assay, and immunoblotting

For total cell labeling, the cells were fixed in 4\% paraformaldehyde (PFA) for $10 \mathrm{~min}$ at room temperature (RT), blocked and permeabilized with $2 \%$ goat serum, $2 \%$ fish skin gelatin, $0.025 \%$ Triton X-100, and $1 \%$ bovine serum albumin in phosphatebuffered saline (PBS). The cells were incubated overnight at $4{ }^{\circ} \mathrm{C}$ with affinity-purified antibodies against $\mathrm{Cx} 43(\mathrm{CT})$ (1:300 dilution) and integrin $\beta 3$ (1:500 dilution) and then with the appropriate secondary antibody for $1 \mathrm{~h}$. For cell surface labeling, cultured cells were washed with PBS and then incubated with cold a-MEM supplemented with $2.5 \% \mathrm{FBS}, 2.5 \% \mathrm{BCS}, 10 \mathrm{mmol} \cdot \mathrm{L}^{-1} \mathrm{HEPES}$, and an integrin $\mathrm{aV}$ inhibitory antibody (1:500 dilution) at $4{ }^{\circ} \mathrm{C}$ for $1 \mathrm{~h}$. The cells were rinsed 3 times with PBS, fixed in 4\% PFA, blocked and permeabilized, and then labeled with secondary antibodies in succession for $1 \mathrm{~h}$ each at RT. Slides were mounted using Vectashield Mounting Medium (H-1000, Vector Laboratories), and confocal fluorescence imaging was performed using a confocal laser scanning microscope (Fluoview; Olympus Optical, Tokyo, Japan).

MLO-Y4 cells cultured for $48 \mathrm{~h}$ were subjected to FSS, and integrin activation assays were performed according to a previously published method. ${ }^{29}$ Briefly, FSS-treated cells were incubated with antibodies targeting GST-FNIII ${ }_{9-11}\left(20 \mu \mathrm{g} \cdot \mathrm{mL}^{-1}\right)$, WOW-1 (1:100 dilution), or inactive aV for $30 \mathrm{~min}$ at $37^{\circ} \mathrm{C}$. Next, the cells were fixed with $2 \%$ PFA and then incubated with secondary antibodies propagated in goats, including Alexa488-conjugated anti-mouse immunoglobulin G (lgG) for WOW1, Alexa 488conjugated anti-Armenian hamster IgG for the $\mathrm{aV}$ inhibitory antibody, rhodamine-conjugated anti-mouse lgG for integrin $\beta 3$, and rhodamine-conjugated anti-rabbit IgG for $\mathrm{C} \times 43$. To assess the involvement of $\mathrm{PI} 3 \mathrm{~K}$ signaling, cells were pretreated with the PI3K inhibitor LY294002 for 30 min prior to FSS and then incubated with GST-FNIII ${ }_{9-11}$, WOW-1, or inactive integrin aV as described above.

For immunoblotting assays, cultured MLO-Y4 cells were lysed in lysis buffer $\left(5 \mathrm{mmol} \cdot \mathrm{L}^{-1}\right.$ Tris, $5 \mathrm{mmol} \cdot \mathrm{L}^{-1}$ EDTA/ethylene glycol tetraacetic acid, $\mathrm{pH} 8.0$ ), and cell lysates were immunoblotted with an anti-AKT (1:1 000 dilution), anti-phospho-AKT (1:1 000 dilution), anti-integrin a5 (1:1 000 dilution), anti-SOST (1:1 000 dilution), anti$\beta$-actin (1:500 dilution), or anti-glyceraldehyde 3-phosphate dehydrogenase (1:5 000 dilution) antibody. Crude membrane extracts were prepared by centrifugation at $100000 \times g$ for 30 min, immunoblotted with an antibody and detected by corresponding secondary antibodies and enhanced chemiluminescence (Amersham Pharmacia Biotech, Piscataway, NJ).

FSS and a mechanical loading assay on transwell filters FSS was created by parallel plate flow chambers separated by a gasket of defined thickness with gravity-driven fluid flow using a peristaltic pump as previously described. ${ }^{38}$ The thickness of the gasket determined the channel height. By adjusting the channel height and flow rate, stress levels of 8 and 16 dynes per $\mathrm{cm}^{2}$ were generated. Controls consisted of MLO-Y4 cells in S-minimum essential medium (SMEM) not subjected to FSS, and the circulating medium was SMEM. The entire flow system was encased within a $\mathrm{CO}_{2}$ incubator at $5 \% \mathrm{CO}_{2}$ and $37^{\circ} \mathrm{C}$.

The mechanical stimulation of MLO-Y4 or differentiated IDGSW3 cells in transwell inserts was conducted by solution dropping as described previously. ${ }^{21}$ Briefly, $50 \mu \mathrm{L}$ of SMEM was passed through a pipette from a height of $5.7 \mathrm{~cm}$ in the center and at three edges of the membrane (four drops total per well) from either side of the filter. The filters were then placed on their side in a clean well with $500 \mu \mathrm{L}$ of either SMEM or the dye solution, $50 \mu \mathrm{mol} \cdot \mathrm{L}^{-1} \mathrm{EtBr}$. After washing with PBS, the cells were fixed with $2 \%$ PFA. The transwell membrane was then peeled from the inserts and mounted onto glass slides using Vectashield Mounting Medium (H-1000, Vector Laboratories). Images were taken with a Zeiss Epifluorescence microscope using the appropriate filters. 
Integrin a5 siRNA treatment

MLO-Y4 cells were trypsinized, resuspended in antibiotic-free OPTI medium (Invitrogen, Carlsbad, CA), and then transiently transfected with integrin a5 siRNA or scrambled siRNA (Ambion, Austin, TX) using a siRNA transfection kit (Ambion). The cells were harvested at $48 \mathrm{~h}$ after transfection and assessed for the expression of integrin a5 and $\beta$-actin or $\mathrm{HC}$ activity utilizing dye uptake.

Generation of osteocyte-specific Cx43 and a5 conditional knockout mice and in vivo injection of integrin antibodies We generated Cx43 osteocyte-specific conditional knockout (cKO) mice (DMP1-Cre; $\mathrm{C} \times 43^{\mathrm{fl} /-}$ ) as previously described. ${ }^{55}$ Mice with heterozygous ITGA5 $\left(\mathrm{a}^{+/-}\right)$gene deletion and the floxed ITGA5 gene $\left(a 5^{f l / f l x}\right)$ were generated and generously provided by the laboratory of Dr. Richard Hynes. ${ }^{56}$ Mice with an osteocyte deletion of the a5 integrin were generated using the Cre/Lox system. First, mice with a floxed ITGA5 gene $\left(a 5^{f(1 / f)}\right)$ were crossed with $a 5$ heterozygous mice expressing one ITGA5 allele $\left(\mathrm{a}^{+/-}\right)$. We then crossed mice expressing a Cre recombinase driven by a 10-kb DMP1 promoter, which leads to gene expression predominantly in osteocytes, $^{34}$ (DMP1-Cre) with $a 5^{\text {flx/- }}$ mice to generate a5 osteocyte-specific conditional knockout mice (DMP1-Cre; $\mathrm{Cx}^{\mathrm{flx} /-}$ ) or (DMP1-Cre; $a 5^{f(x /-}$ ). Genotyping was performed by polymerase chain reaction techniques using genomic DNA isolated from mouse tails and corresponding primers synthesized at the UTHSCSA DNA Core Facility.

In vivo tibial compression model

We subjected 4-month-old WT and Cx43 transgenic mice to mechanical loading through tibial compression ${ }^{57-61}$ using a loading setup established in our laboratory. For WT mice, we also intraperitoneally (IP) injected the aV inhibitory antibody (H9.2B8) at a concentration of $25 \mathrm{mg} \cdot \mathrm{kg}^{-1}$. Mice were subjected to tibial loading at a frequency of $2 \mathrm{~Hz}$ using a haversine waveform for 600 cycles with a constant force $(8.86 \mathrm{~N}$ for control mice and $7.44 \mathrm{~N}$ for Cre- $a 5^{f(x / n u l l}$ mice) for $5 \mathrm{~min}$. We applied dynamic peak loads to achieve $1200 \mu \varepsilon$.

In vitro and in vivo dye uptake assays

MLO-Y4 cells, differentiated IDG-SW3 cells, and primary osteocytes isolated from WT and transgenic mice were subjected to FSS for $10 \mathrm{~min}$, liquid dropping, or treatment with $5 \mathrm{ng} \cdot \mathrm{mL}^{-1}$ insulin-like growth factor 1 (IGF-1) for $30 \mathrm{~min}$. Dye uptake experiments were performed as described previously. ${ }^{14}$ Briefly, the cells were incubated with $50 \mu \mathrm{mol} \cdot \mathrm{L}^{-1} \mathrm{EtBr}$ dye mixture for $5 \mathrm{~min}$, and the mean intensity of the nuclear region was determined using ImageJ software (NIH). Cells cultured for $48 \mathrm{~h}$ were preincubated with the antibody blocking integrin $\mathrm{aV}$ activation $\left(0.5 \mathrm{ng} \cdot \mathrm{mL}^{-1}\right)$ or the $\mathrm{Cx} 43$ (E2) antibody $\left(2 \mu \mathrm{g} \cdot \mathrm{mL}^{-1}\right)$ for $30 \mathrm{~min}$. To provide accurate assessments of HC activity among different assays, we presented dye uptake amounts as fold changes over the basal controls.

In vivo dye uptake assays were conducted with 4-month-old WT, Cx43, and a5 cKO mice; a second group of WT mice was also treated with the aV inhibitory antibody. Mouse tibial compressions were performed on the left leg, and the right leg was used as an unloaded control. The aV inhibitory antibody $\left(25 \mathrm{mg} \cdot \mathrm{kg}^{-1}\right)$ was IP injected $4 \mathrm{~h}$ before Evans blue injection. Mice were intravenously (IV) injected with Evans blue dye $\left(200 \mathrm{mg} \cdot \mathrm{kg}^{-1}\right)$ via the tail vein. Thirty minutes after IV injection, tibial compression was performed, and $1 \mathrm{~h}$ later, the mice were sacrificed with isoflurane and perfused with PBS through the left ventricle of the heart. The volume of PBS used for perfusion was $\sim 3$ times the blood volume to remove the excess dye in the blood. Then, the animals were perfused with $4 \%$ PFA ( 3 times the blood volume) to fix the tissues, followed by perfusion with PBS to remove excess PFA in the mouse body system. Tibial bones were collected, decalcified with $10 \%$ EDTA ( $\mathrm{pH}$ 7.4) for 2 weeks, embedded in optimum cutting temperature compound, and frozen in liquid nitrogen for cryostat tissue sectioning. Frozen tissue sections of $12 \mu \mathrm{m}$ thickness were prepared and counterstained with 4',6-diamidino-2-phenylindole (DAPI, $1 \mu \mathrm{g} \cdot \mathrm{mL}^{-1}$ for $5 \mathrm{~min}$ ) before imaging on a fluorescence microscope. Evans blue dye uptake in the cortical bone area was analyzed by measuring the fluorescence intensities of 20 cells per section ( 3 sections per mouse), and images were quantified by ImageJ software.

Statistical analysis

All data were analyzed using GraphPad Prism 5.04 software (GraphPad). One-way ANOVA and the Student-Newman Keul's test were used for comparisons of two or more groups, and the unpaired Student's t-test was used for comparisons between two groups. Unless otherwise specified in the figure legends, the data are presented as the means \pm SEMs of at least three experiments. An asterisks indicate the degree of significance compared with the controls $\left({ }^{*}, P<0.05,{ }^{*}, P<0.01,{ }^{* *}, P<0.001\right)$.

\section{ACKNOWLEDGEMENTS}

We thank Dr. Richard O. Hynes at the Massachusetts Institute of Technology for generously providing the heterozygous ITGA5 $\left(\mathrm{a}^{+/-}\right)$gene deletion and floxed ITGA5 gene $\left(a 5^{f(x / f l x}\right)$ mouse strains, Dr. Sanford Shattil at the University of California at San Diego for generously providing the WOW-1 integrin antibody and Dr. Martin A. Schwartz at Yale University for generously providing GST-FNIII $\left.\right|_{9-11}$. We thank Dr. Mark Shapiro at UTHSCSA for the technical advice and assistance and Dr. Eduardo Cardenas and Dr. Francisca Acosta at UTHSCSA for critically reading and editing the paper. This work was supported by the National Institutes of Health (NIH) grant AR072072 (to J.X.J.) and the Welch Foundation grant AQ-1507 (to J.X.J.). We also thank the UTHSCSA CMMI and the UTHSCSA Optical Imaging Facility supported by the Cancer Therapy and Research Center for the support provided from the NIH-National Cancer Institute P30 award CA054174 and Texas state funds.

\section{AUTHOR CONTRIBUTIONS}

M.A.R. and J.X.J. designed the study. M.A.R., R. H, and G.S. performed the experiments and analyzed the data. J.X.J. wrote the manuscript, which was reviewed, commented on and approved by all authors.

\section{ADDITIONAL INFORMATION}

Supplementary information The online version of this article (https://doi.org/ $10.1038 /$ s41413-020-00126-w) contains supplementary material, which is available to authorized users.

Competing interests: The authors declare no competing interests.

\section{REFERENCES}

1. Srinivasan, S., Gross, T. S. \& Bain, S. D. Bone mechanotransduction may require augmentation in order to strengthen the senescent skeleton. Ageing Res. Rev. 11, 353-360 (2012).

2. Rochefort, G. Y., Pallu, S. \& Benhamou, C. L. Osteocyte: the unrecognized side of bone tissue. Osteoporos Int. 21, 1457-1469 (2010).

3. Bonewald, L. F. The amazing osteocyte. J. Bone Miner. Res. 26, 229-238 (2011).

4. Rochefort, G. Y. The osteocyte as a therapeutic target in the treatment of osteoporosis. Ther. Adv. Musculoskelet. Dis. 6, 79-91 (2014).

5. Bonewald, L. F. Generation and function of osteocyte dendritic processes. J. Musculoskelet. Neuronal Interact. 5, 321-324 (2005).

6. Burger, E. H. \& Klein-nulend, J. Mechanotransduction in bone-role of the lacunocanalicular network. FASEB J. 13, S101-S112 (1999).

7. Turner, C. H., Robling, A. G., Duncan, R. L. \& Burr, D. B. Do bone cells behave like a neuronal network? Calcif. Tissue Int 70, 435-442 (2002).

8. Fritton, S. P. \& Weinbaum, S. Fluid and solute transport in bone: flow-induced mechanotransduction. Annu. Rev. Fluid Mech. 41, 347-374 (2009).

9. Jacobs, C. R., Temiyasathit, S. \& Castillo, A. B. Osteocyte mechanobiology and pericellular mechanics. Annu. Rev. Biomed. Eng. 12, 369-400 (2010).

10. Cowin, S. C., Moss-Salentijin, L. \& Moss, M. L. Candidates for the mechanosensory system in bone. J. Biomed. Eng. 113, 191-197 (1991).

11. Knothe Tate, M. L. "Whither flows the fluid in bone?" An osteocyte's perspective. J. Biomech. 36, 1409-1424 (2003). 
12. Jiang, J. X., Siller-Jackson, A. J. \& Burra, S. Roles of gap junctions and hemichannels in bone cell functions and in signal transmission of mechanical stress. Front. Biosci. 12, 1450-1462 (2007).

13. Goodenough, D. A. \& Paul, D. L. Beyond the gap: functions of unpaired connexon channels. Nat. Rev. Mol. Cell Biol. 4, 285-294 (2003).

14. Cherian, P. P. et al. Mechanical strain opens connexin 43 hemichannels in osteocytes: a novel mechanism for the release of prostaglandin. Mol. Biol. Cell 16, 3100-3106 (2005).

15. Genetos, D. C., Kephart, C. J., Zhang, Y., Yellowley, C. E. \& Donahue, H. J. Oscillating fluid flow activation of gap junction hemichannels induces ATP release from MLO-Y4 osteocytes. J. Cell Physiol. 212, 207-214 (2007).

16. Baylink, T. M., Mohan, S., Fitzsimmons, R. J. \& Baylink, D. J. Evaluation of signal transduction mechanisms for the mitogenic effects of prostaglandin E2 in normal human bone cells in vitro. J. Bone Min. Res 11, 1413-1418 (1996)

17. Keller, J., Klamer, A., Bak, B. \& Suder, P. Effects of local prostaglandin $E_{2}$ on fracture callus in rabbit. Acta Orthop. Scand. 64, 59-63 (1993).

18. Jee, W. S. S., Ueno, K., Deng, Y. P. \& Woodbury, D. M. The effects of prostaglandin E2 in growing rats: increased metaphyseal hard tissue and corticoendosteal bone formation. Calcif. Tissue Int 37, 148-156 (1985).

19. Siller-Jackson, A. J. et al. Adaptation of connexin 43-hemichannel prostaglandin release to mechanical loading. J. Biol. Chem. 283, 26374-26382 (2008).

20. $\mathrm{Xu}, \mathrm{H}$. et al. Connexin 43 channels are essential for normal bone structure and osteocyte viability. J. Bone Miner. Res. 30, 436-448 (2015).

21. Burra, S. et al. Dendritic processes of osteocytes are mechanotransducers that induce the opening of hemichannels. Proc. Natl Acad. Sci. 107, 13648-13653 (2010).

22. Batra, N. et al. Mechanical stress-activated integrin alpha5beta1 induces opening of connexin 43 hemichannels. Proc. Natl Acad. Sci. USA 109, 3359-3364 (2012).

23. Batra, N. et al. Direct regulation of osteocytic connexin 43 hemichannels through AKT kinase activated by mechanical stimulation. J. Biol. Chem. 289, 10582-10591 (2014)

24. Han, Y., Cowin, S. C., Schaffler, M. B. \& Weinbaum, S. Mechanotransduction and strain amplification in osteocyte cell processes. Proc. Nat. Acad. Sci. USA 101, 16689-16694 (2004).

25. Wang, Y., McNamara, L. M., Schaffler, M. B. \& Weinbaum, S. A model for the role of integrins in flow induced mechanotransduction in osteocytes. Proc. Nat. Acad. Sci. USA 104, 15941-15946 (2007).

26. Wang, Y., McNamara, L. M., Shaffler, M. B. \& Weinbaum, S. Strain amplification and integrin based signaling in osteocytes. J. Musculoskelet. Neuronal Interact. 8, 332-334 (2008)

27. Thi, M. M., suadicani, S. O., Schaffler, M. B., Weinbaum, S. \& Spray, D. C Mechanosensory responses of osteocytes to physiological forces occur along processes and not cell body and require alphaVbeta3 integrin. Proc. Natl Acad. Sci. USA 110, 21012-21017 (2013).

28. McNamara, L. M., Majeska, R. J., Weinbaum, S., Friedrich, V. \& Schaffler, M. B. Attachment of osteocyte cell processes to the bone matrix. Anat. Rec. 292 355-363 (2009)

29. Orr, A. W., Ginsberg, M. H., Shattil, S. J., Deckmyn, H. \& Schwartz, M. A. Matrixspecific suppression of integrin activation in shear stress signaling. Mol. Biol. Cell 17, 4686-4697 (2006)

30. Veron, D. et al. Acute podocyte vascular endothelial growth factor (VEGF-A) knockdown disrupts alphaVbeta3 integrin signaling in the glomerulus. PLOS ONE 7, e40589 (2012).

31. Schultz, J. F. \& Armant, D. R. Beta 1- and beta 3-class integrins mediate fibronectin binding activity at the surface of developing mouse peri-implantation blastocysts. Regulation by ligand-induced mobilization of stored receptor. J. Biol. Chem. 270, 11522-11531 (1995).

32. Woo, S. M., Rosser, J., Dusevich, V., Kalajzic, I. \& Bonewald, L. F. Cell line IDG-SW3 replicates osteoblast-to-late-osteocyte differentiation in vitro and accelerates bone formation in vivo. J. Bone Miner. Res. 26, 2634-2646 (2011).

33. Semenov, M., Tamai, K. \& He, X. SOST is a ligand for LRP5/LRP6 and a Wnt signaling inhibitor. J. Biol. Chem. 280, 26770-26775 (2005).

34. Yang, W. et al. Dentin matrix protein 1 gene cis-regulation: use in osteocytes to characterize local responses to mechanical loading in vitro and in vivo. J. Biol. Chem. 280, 20680-20690 (2005)

35. Geoghegan, I. P., Hoey, D. A. \& McNamara, L. M. Estrogen deficiency impairs integrin $a(v) \beta(3)$-mediated mechanosensation by osteocytes and alters osteoclastogenic paracrine signalling. Sci. Rep. 9, 4654 (2019).

36. Haugh, M. G., Vaughan, T. J. \& McNamara, L. M. The role of integrin a(V) $\beta(3)$ in osteocyte mechanotransduction. J. Mech. Behav. Biomed. Mater. 42, 67-75 (2015).

37. Lu, X. L., Huo, B., Park, M. \& Guo, X. E. Calcium response in osteocytic networks under steady and oscillatory fluid flow. Bone 51, 466-473 (2012).

38. Cheng, B. et al. Expression of functional gap junctions and regulation by fluid flow in osteocyte-like MLO-Y4 cells. J. Bone Min. Res 16, 249-259 (2001)
39. Galea, G. L. et al. Old age and the associated impairment of bones' adaptation to loading are associated with transcriptomic changes in cellular metabolism, cellmatrix interactions and the cell cycle. Gene 599, 36-52 (2017).

40. Galea, G. L. et al. Sost down-regulation by mechanical strain in human osteoblastic cells involves PGE2 signaling via EP4. FEBS Lett. 585, 2450-2454 (2011).

41. Hanks, S. K., Ryzhova, L., Shin, N. Y. \& Brabek, J. Focal adhesion kinase signaling activities and their implications in the control of cell survival and motility. Front Biosci. 8, d982-d996 (2003).

42. Xia, X. et al. Prostaglandin promotion of osteocyte gap junction function through transcriptional regulation of connexin 43 by glycogen synthase kinase 3 / $\beta$-catenin signaling. Mole. Cell. Biol. 30, 206-219 (2010).

43. Bonewald, L. F. \& Johnson, M. L. Osteocytes, mechanosensing and Wnt signaling. Bone 42, 606-615 (2008).

44. Grimston, S. K. et al. Role of connexin43 in osteoblast response to physical load. Ann. N. Y. Acad. Sci. 1068, 214-224 (2006).

45. Grimston, S. K., Watkins, M. P., Brodt, M. D., Silva, M. J. \& Civitelli, R. Enhanced periosteal and endocortical responses to axial tibial compression loading in conditional connexin43 deficient mice. PLoS One 7, e44222 (2012).

46. Zhang, Y. et al. Enhanced osteoclastic resorption and responsiveness to mechanical load in gap junction deficient bone. PLoS One 6, e23516 (2011).

47. Bivi, N. et al. Absence of $\mathrm{C} \times 43$ selectively from osteocytes enhances responsiveness to mechanical force in mice. J. Orthop. Res.: Off. Publ. Orthop. Res. Soc. 31, 1075-1081 (2013).

48. Grimston, S. K., Brodt, M. D., Silva, M. J. \& Civitelli, R. Attenuated response to in vivo mechanical loading in mice with conditional osteoblast ablation of the connexin43 gene (Gja1). J. Bone Min. Res 23, 879-886 (2008).

49. Kanjanamekanant, K., Luckprom, P. \& Pavasant, P. P2X7 receptor-Pannexin1 interaction mediates stress-induced interleukin-1 beta expression in human periodontal ligament cells. J. periodontal Res. 49, 595-602 (2014).

50. Seref-Ferlengez, Z. et al. Role of pannexin 1 channels in load-induced skeletal response. Ann. N. Y. Acad. Sci. 1442, 79-90 (2019).

51. Li, X. et al. Stimulation of Piezo1 by mechanical signals promotes bone anabolism. elife 8, e49631 (2019).

52. Qin, L., Liu, W., Cao, H. \& Xiao, G. Molecular mechanosensors in osteocytes. Bone Res. 8, 23 (2020).

53. Kato, Y., Windle, J. J., Koop, B. A., Mundy, G. R. \& Bonewald, L. F. Establishment of an osteocyte-like cell line, MLO-Y4. J. Bone Miner. Res 12, 2014-2023 (1997).

54. Stern, A. R. et al. Isolation and culture of primary osteocytes from the long bones of skeletally mature and aged mice. Biotechniques 52, 361-373 (2012).

55. Zhou, J. Z. et al. Osteocytic connexin hemichannels suppress breast cancer growth and bone metastasis. Oncogene 35, 5597-5607 (2016).

56. van der Flier, A. et al. Endothelial alpha5 and alphav integrins cooperate in remodeling of the vasculature during development. Development 137, 2439-2449 (2010).

57. Lynch, M. E. et al. Cancellous bone adaptation to tibial compression is not sex dependent in growing mice. J. Appl. Physiol. (1985) 109, 685-691 (2010).

58. Niziolek, P. J., Warman, M. L. \& Robling, A. G. Mechanotransduction in bone tissue: The A214V and G171V mutations in Lrp5 enhance load-induced osteogenesis in a surface-selective manner. Bone 51, 459-465 (2012).

59. Lynch, M. E. et al. Tibial compression is anabolic in the adult mouse skeleton despite reduced responsiveness with aging. Bone 49, 439-446 (2011).

60. Sugiyama, T., Price, J. S. \& Lanyon, L. E. Functional adaptation to mechanical loading in both cortical and cancellous bone is controlled locally and is confined to the loaded bones. Bone 46, 314-321 (2010).

61. Main, R. P., Lynch, M. E. \& van der Meulen, M. C. In vivo tibial stiffness is maintained by whole bone morphology and cross-sectional geometry in growing female mice. J. Biomech. 43, 2689-2694 (2010).

Open Access This article is licensed under a Creative Commons Attribution 4.0 International License, which permits use, sharing, adaptation, distribution and reproduction in any medium or format, as long as you give appropriate credit to the original author(s) and the source, provide a link to the Creative Commons license, and indicate if changes were made. The images or other third party material in this article are included in the article's Creative Commons license, unless indicated otherwise in a credit line to the material. If material is not included in the article's Creative Commons license and your intended use is not permitted by statutory regulation or exceeds the permitted use, you will need to obtain permission directly from the copyright holder. To view a copy of this license, visit http://creativecommons. org/licenses/by/4.0/.

(c) The Author(s) 2021 